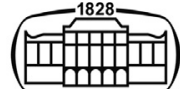

AKADÉMIAI KIADÓ

\section{Acta Veterinaria Hungarica}

68 (2020) 2, 169-176

DOI:

$10.1556 / 004.2020 .00032$

(C) 2020 Akadémiai Kiadó, Budapest

\title{
Diagnostic utility of different models used to assess the acid-base balance in cats with chronic kidney disease
}

\section{PIOTR SŁAWUTA* $\odot$, AGNIESZKA SIKORSKA-KOPYŁOWICZ and GRZEGORZ SAPIKOWSKI}

Department of Internal Medicine and Clinic of Diseases of Horses, Dogs and Cats, The Faculty of Veterinary Medicine, Wrocław University of Environmental and Life Science, Norwida 32, 50-375, Wrocław, Poland

Received: November 21, 2019 • Accepted: May 06, 2020

Published online: August 28, 2020

\section{ORIGINAL ARTICLE}

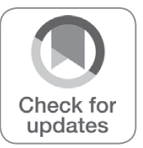

*Corresponding author.

E-mail: piotr.slawuta@upwr.edu.pl Tel.: +48713205360

\section{KEYWORDS}

acid-base balance, anion gap, cats, CKD, metabolic acidosis

\section{INTRODUCTION}

Chronic kidney disease (CKD) commonly affects domestic cats (Brown et al., 2016). A study carried out in the United Kingdom has found that CKD is diagnosed in $40 \%$ of domestic cats older than 10 years of age (Sparkes et al., 2016). It is believed that the high mortality rate associated with CKD is due to the inability to staunch histopathological changes in the renal parenchyma, as well as to complications associated with metabolic acidosis (Chakrabarti et al., 2012; Hopper and Epstein, 2012; McLeland et al., 2015). Metabolic acidosis occurs commonly with CKD due to the retention of acids that are excreted normally by the kidneys if the glomerular filtration rate (GFR) is normal (Bartges, 2012). It is assumed that the GFR in healthy cats ranges from 1.30 to $1.40 \mathrm{~mL} / \mathrm{kg} / \mathrm{min}$ although it is rarely assessed clinically (Finch, 2014). Hence, it is often difficult to identify metabolic acidosis in the course of CKD, rendering its diagnosis and treatment impossible (De Brito-Ashurst et al., 2009; Di Iorio et al., 2012).

Previous studies in cats show that metabolic acidosis develops with the progression of CKD and is usually diagnosed at its last stage (Elliott et al., 2003; Bartges, 2012; Reynolds and Lefebvre, 2013). Human studies suggest that mild to moderate metabolic acidosis occurs in the majority of patients with CKD, which is thought to be caused by the fact that the 
concentration of the carbonate buffer $\left(\mathrm{HCO}_{3}{ }^{-}\right)$rarely decreases below $12 \mathrm{mmol} / \mathrm{L}$ (Kraut and Kurtz, 2005; Dębowska et al., 2013).

The standard diagnosis of metabolic acidosis using the Hendersson-Hasselbalch formula is based on an analysis of the elements of the carbonic acid-bicarbonate buffer system in arterial blood (in veterinary practice often in venous blood). This model includes the measurement of the $\mathrm{pH}$ value and the partial pressure of carbon dioxide $\left(\mathrm{pCO}_{2}\right)$ and using the calculated value of $\mathrm{HCO}_{3}{ }^{-}$. Based on the classic model, metabolic acidosis is characterised by a primary decrease in the concentration of $\mathrm{HCO}_{3}{ }^{-}$and a compensatory decrease in $\mathrm{pCO}_{2}$ caused by an increased respiratory rate, leading to $\mathrm{pH}$ normalisation (Kellum, 2000). Clinical evidence suggests that changes in $\mathrm{HCO}_{3}{ }^{-}$concentration occur at such a late stage of the disease that it is futile to supplement bicarbonates and taurine orally even though they inhibit the pathologic processes in the kidneys (De Brito-Ashurst et al., 2009; Di Iorio et al., 2012; Han and Chesney, 2012). Studies performed on cats have shown that metabolic acidosis is diagnosed in advanced-stage CKD using the classic model (Elliott et al., 2003; Paepe and Daminet, 2013).

Acid-base balance $(\mathrm{ABB})$ disturbances may also be diagnosed based on the serum concentration of selected ions $\left(\mathrm{Na}^{+}, \mathrm{K}^{+}, \mathrm{Cl}^{-}, \mathrm{HCO}_{3}{ }^{-}\right.$, albumins) in order to determine the anion gap ( $\mathrm{AG}$, i.e. the concentration of unmeasured anions), the corrected $\mathrm{AG}\left(\mathrm{AG}_{\mathrm{corr}}\right)$ which also uses the albumin concentration and the chloride/sodium ratio $\left(\mathrm{Cl}^{-} / \mathrm{Na}^{+}\right)$ of the serum. Resulting from the low electroneutrality, the concept of the AG is closely related to the analysis of the ABB based on the classic model (Constable, 2000; Kraut and Madias, 2007; Morris and Low, 2008). The AG usually increases in the course of metabolic acidosis (Morris and Low, 2008). This is associated with a decreased concentration of $\mathrm{HCO}_{3}{ }^{-}$caused by a lower exploitation of the $\mathrm{HCO}_{3}{ }^{-}$buffer which binds $\mathrm{H}^{+}$(Smuszkiewicz and Jakieła-Sokołowska, 2011). However, a decrease in serum $\mathrm{HCO}_{3}{ }^{-}$concentration may sometimes be accompanied by a compensatory increase in the serum chloride ion $\left(\mathrm{Cl}^{-}\right)$concentration, with the AG remaining unchanged (Kraut and Kurtz, 2005). Hence, metabolic acidosis is classified as a normal anion gap (or hyperchloraemic) metabolic acidosis or a high anion gap (or normochloraemic) metabolic acidosis (Casaletto, 2005; Emmett, 2006; Kraut and Madias, 2007). Less often, an elevated serum anion gap is caused by a laboratory error, accumulation of anionic paraproteins, metabolic alkalosis and severe hyperphosphataemia (Kraut and Madias, 2007). Studies in dogs and cats have shown that the AG value increases in about $30 \%$ of patients with diagnosed metabolic acidosis (Hopper et al., 2014b). It has also been found that the AG value may decrease in cats with advanced-stage CKD (Paepe and Daminet, 2013).

The AG value does not take into account the concentration of the blood protein (especially albumin) buffer, which should be considered in the assessment of metabolic acid-base disorders, as the serum albumin concentration often decreases in the course of such disorders. Hence, the corrected $\mathrm{AG}\left(\mathrm{AG}_{\text {corr }}\right)$ is calculated in the clinical practice, as it takes into account the AG with relation to the patient's current serum albumin concentration (Morgan, 2009; Smuszkiewicz and Jakieła-Sokołowska, 2011). Some authors claim that the AG has no diagnostic value without this correction (Feldman et al., 2005).

The ABB of an organism can also be described by the Stewart model (Strong Ion Approach), which assumes that body water is the most important and inexhaustible source of hydrogen ions that form from the dissociation of water. Hence, plasma $\mathrm{pH}$ changes result entirely from a change in the degree of water dissociation, affected not only by $\mathrm{pCO}_{2}$, albumin and phosphate but also by the difference in the concentration of fully dissociated ions, i.e. the strong ion difference (SID) (Morgan, 2009). This, in turn, is determined by the concentration of $\mathrm{Na}^{+}$and $\mathrm{Cl}^{-}$(Stewart, 1978, 1983; Constable, 2000). This assumption is used to rapidly diagnose $\mathrm{ABB}$ based on the blood chloride/sodium ratio $\left(\mathrm{Cl}^{-} / \mathrm{Na}^{+}\right)$, assuming that the blood serum concentration of the remaining fully dissociated ions is relatively low compared with that of $\mathrm{Na}^{+}$and $\mathrm{Cl}^{-}$in a human study (Kraut and Madias, 2007; Morgan, 2009). Values below 0.75 indicate alkalosis, while those above 0.80 indicate acidosis (Fencl et al., 2000). Goggs et al. (2017) and Vanova-Uhrikova et al. (2017) also supported this idea in their experiment on dogs and cats. The diagnostic criteria for metabolic acidosis used in this study are presented in Table 1.

Symmetric dimethylarginine (SDMA) has been shown to be an accurate and precise biomarker for calculating estimated GFR in humans, as well as a more sensitive biomarker than creatinine for assessing renal dysfunction (Hall et al., 2014). The concentration of SDMA in feline blood is frequently used as an endogenous surrogate marker in research studies as well as in the clinical practice. This is due to the fact that the concentration of SDMA in the blood (unlike that of creatinine) is independent of the animal's muscle mass and age, and does not correlate with the lean body mass (Hall et al., 2014; Hokamp and Nabity, 2016).

The aim of this study was to carry out a comparative analysis of the utility of the classic model, $A G, A_{\text {corr }}$ and the $\mathrm{Cl}^{-} / \mathrm{Na}^{+}$ratio in the diagnosis of acid-base disorders in cats with CKD.

\section{MATERIALS AND METHODS}

This retrospective study was carried out on 100 neutered cats of different breeds (74 European Shorthair, 10 Persian, 6 British Shorthair, 4 Siamese cat, 3 Devon Rex, 3 Maine Coon) of both sexes ( 64 males, 46 females) from seven to nine years old (mean $=8.1, \mathrm{SD}=0.75)$, with a body weight from 2.5 to $9.2 \mathrm{~kg}$ (mean $=4.37, \mathrm{SD}=1.08$ ). The control group (Group C) consisted of 20 healthy, neutered cats with normal serum creatinine, SDMA and urea concentrations. The study group consisted of 80 neutered domestic cats of both sexes from seven to nine years old, which were 
Table 1. Diagnostic criteria for metabolic acidosis for the traditional and Stewart's acid-base analysis

\begin{tabular}{|c|c|c|c|}
\hline \multicolumn{4}{|c|}{ Diagnostic criteria for metabolic acidosis } \\
\hline \multicolumn{2}{|c|}{ Classic model } & \multicolumn{2}{|c|}{$\begin{array}{l}\text { Stewart's } \\
\text { analysis }\end{array}$} \\
\hline $\mathrm{pH}^{\mathrm{a}}$ & $\begin{array}{l}\text { Usually without } \\
\text { changes }\end{array}$ & SID & $<40^{\mathrm{b}}$ \\
\hline $\mathrm{pCO}_{2}{ }^{\mathrm{a}}$ & $\begin{array}{l}\text { Below reference } \\
\text { ranges }\end{array}$ & $\begin{array}{l}\mathrm{Cl}^{-} / \\
\mathrm{Na}^{+}\end{array}$ & $>0.8^{\mathrm{c}}$ \\
\hline $\mathrm{HCO}_{3}{ }^{-\mathrm{a}}$ & $\begin{array}{l}\text { Below reference } \\
\text { ranges }\end{array}$ & & \\
\hline $\begin{array}{l}\text { Metabolic acidosis associated } \\
\text { with increased } \mathrm{AG}^{\mathrm{b}}\end{array}$ & $\mathrm{AG}>20 \mathrm{mmol} / \mathrm{L}$ & & \\
\hline $\begin{array}{l}\text { Metabolic acidosis not } \\
\text { associated with increased } \\
\mathrm{AG}^{\mathrm{b}}\end{array}$ & $\mathrm{AG} \leq 20 \mathrm{mmol} / \mathrm{L}$ & & \\
\hline
\end{tabular}

$\mathrm{pCO}_{2}$ - partial pressure of $\mathrm{CO}_{2}$ in arterial blood; $\mathrm{HCO}_{3}{ }^{-}$

-bicarbonate concentration in arterial blood; $\mathrm{AG}=\left(\mathrm{Na}^{+}+\mathrm{K}^{+}\right)$$\left(\mathrm{Cl}^{-}-\mathrm{HCO}_{3}{ }^{-}\right) ; \mathrm{SID}=\left(\mathrm{Na}^{+}+\mathrm{K}^{+}\right)-\left(\mathrm{Cl}^{-}\right) ; \mathrm{Cl}^{-} / \mathrm{Na}^{+}=\left(\mathrm{Cl}^{-}\right)$: $\left(\mathrm{Na}^{+}\right)$.

${ }^{a}$ According to Kellum (2000).

${ }^{\mathrm{b}}$ According to Hopper et al. (2014a).

${ }^{\mathrm{c}}$ According to Fencl et al. (2000).

diagnosed with CKD based on the serum concentrations of creatinine, SDMA and urea. Echocardiography, abdominal ultrasound, urinalysis and urine/protein ratio (UPC) determination were carried out in all cats to exclude acute kidney injury (AKI) and prerenal causes of azotaemia. The animals from the study group were divided into four groups based on the stage of the disease (Groups I, II, III and IV) according to the criteria adopted by the International Renal Interest Society - IRIS (Brown et al., 2016). According to the IRIS guidelines, cats with a persistent increase in SDMA above $14 \mu \mathrm{g} / \mathrm{dL}$ that suggested reduced renal function and/or had serum creatinine concentrations within the reference range that increased in consecutive blood analyses, were

Table 2. Inclusion criteria for grouping cats based on the stage of $\mathrm{CKD}$ in accordance with the IRIS guidelines

\begin{tabular}{|c|c|c|c|c|}
\hline \multirow[b]{2}{*}{ Criterion } & \multicolumn{4}{|c|}{ Stage of CKD } \\
\hline & I & II & III & IV \\
\hline Azotaemia $^{a}$ & $\begin{array}{c}\text { Non- } \\
\text { azotaemic }\end{array}$ & $\begin{array}{c}\text { Mild } \\
\text { azotaemia }\end{array}$ & $\begin{array}{l}\text { Moderate } \\
\text { azotaemia }\end{array}$ & $\begin{array}{c}\text { Severe } \\
\text { azotaemia }\end{array}$ \\
\hline $\begin{array}{l}\text { Blood } \\
\text { creatinine, } \\
\mu \mathrm{mol} / \mathrm{L}^{\mathrm{a}}\end{array}$ & $\leq 140$ & $140-250$ & $251-440$ & $\geq 440$ \\
\hline $\begin{array}{l}\text { SDMA, } \mu \mathrm{g} / \\
\mathrm{dL}^{\mathrm{a}}\end{array}$ & $\geq 14$ & $\geq 25$ & $\geq 45$ & $\begin{array}{c}\text { Exceeding } \\
\text { threshold } \\
\text { value }\end{array}$ \\
\hline $\begin{array}{c}\text { Blood urea, } \\
\mathrm{mmol}^{\mathrm{b}}\end{array}$ & $4.8-10.1$ & $13.1-19.9$ & $20.3-45.5$ & $45.7-54.0$ \\
\hline
\end{tabular}

a IRIS guidelines.

${ }^{\mathrm{b}}$ Range obtained in the present study. included in Group I. Each group consisted of 20 animals, and the division criteria are presented in Table 2. The serum urea concentration was used as an additional indicator of azotaemia (Table 2). Arterial and venous blood was collected from each animal. Arterial blood was collected from the femoral artery. Arterial blood was drawn into heparinised 2$\mathrm{mL}$ syringes using $23 \mathrm{G}$ needles and immediately transported to the laboratory for testing. The samples were transported on ice. The $\mathrm{ABB}$ parameters - $\mathrm{pH}, \mathrm{pCO}_{2}$ and arterial bicarbonate concentration $\left(\mathrm{aHCO}_{3}{ }^{-}\right)$- were assessed using the Osmetech OPTI CCA Blood Gas System (Table 3). Measurements were taken at $37^{\circ} \mathrm{C}$. If necessary, cats were sedated with medetomidine at $10 \mu \mathrm{g} / \mathrm{kg}$ s.c. prior to arterial blood collection. Eighteen cats had to be sedated. According to Congdon et al. (2013), dexmedetomidine administration does not affect the $\mathrm{ABB}$ parameters or the concentrations of $\mathrm{Na}^{+}, \mathrm{K}^{+}$and $\mathrm{Cl}^{-}$in dogs. Hence, animals that had received medetomidine were not excluded from the study group (Congdon et al., 2013). The concentrations of $\mathrm{Na}^{+}, \mathrm{K}^{+}, \mathrm{Cl}^{-}, \mathrm{Pi}, \mathrm{HCO}_{3}{ }^{-}\left(\mathrm{vHCO}_{3}{ }^{-}\right)$, albumin, glucose, lactate, and the activity of ALT, AST and alkaline phosphatase were measured in serum samples (Konelab Prime 30ISE ABC Animal Blood). Complete blood count (CBC) was carried out from venous blood (ABC Animal Blood Counter).

The concentration of blood SDMA was assessed using the enzyme immunoassay method (EIA method) in a reference IDEXX laboratory.

Based on the obtained results, the values of $A G, A_{\text {corr }}$, $\mathrm{Cl}^{-} / \mathrm{Na}^{+}$and SID were calculated according to the formulae provided by other authors (Kraut and Madias, 2007; Smuszkiewicz and Jakieła-Sokołowska, 2011; Vanova-Uhrikova et al., 2017):

$$
\begin{gathered}
\mathrm{SID}=\left(\mathrm{Na}^{+}+\mathrm{K}^{+}\right)-\left(\mathrm{Cl}^{-}\right) \\
\mathrm{AG}=\left(\mathrm{Na}^{+}+\mathrm{K}^{+}\right)-\left(\mathrm{Cl}^{-}-\mathrm{vHCO}_{3}^{-}\right) \\
\mathrm{AG}_{\text {corr }}=\mathrm{AG}+\left(39 \mathrm{~g} / \mathrm{L}-\mathrm{alb}_{\text {act }} \mathrm{g} / \mathrm{L}\right) / 4,
\end{gathered}
$$

where: $39 \mathrm{~g} / \mathrm{L}$ was the upper normal threshold of feline serum albumin concentration and $\mathrm{alb}_{\mathrm{act}}$ was the serum albumin concentration in the studied cats.

$$
\begin{gathered}
\mathrm{AG}_{\text {diff }}=\mathrm{AG}-\mathrm{AG}_{\text {corr }} \\
\mathrm{Cl}^{-} / \mathrm{Na}^{+}=\left(\mathrm{Cl}^{-}\right):\left(\mathrm{Na}^{+}\right)
\end{gathered}
$$

The mean and standard deviation were calculated for all the results. One-way analysis of variance (ANOVA) was used to compare the values of the different groups and assess the statistical differences between them. If the equal mean hypothesis was rejected, a post-hoc Tukey's Honest Significance Different (HSD) test was carried out in order to determine the statistical difference between groups. The significance level was drawn at $5 \%$ and all the analyses were carried out using the Statistica 12 software (StatSoft Poland).

The Local Ethics Committee on Animal Research in Wrocław declared in its resolution 94/2017, on October 25, 
Table 3. A comparison of the mean acid-base balance parameters (with reference values) analysed in arterial blood in the control group (C) and in cats with various stages of CKD (I-IV)

\begin{tabular}{lccrrr}
\hline Parameter & \multicolumn{1}{c}{$\mathrm{C}$} & \multicolumn{1}{c}{ I } & II & III & IV \\
\hline $\mathrm{pH}(7.41-7.46)^{\mathrm{a}}$ & $7.42 \pm 0.04$ & $7.42 \pm 0.01$ & $7.42 \pm 0.09$ & $7.41 \pm 0.02$ & $7.41 \pm 0.08$ \\
$\mathrm{pCO}_{2} \mathrm{mmHg}(26.2-34.8)^{\mathrm{a}}$ & $31.26 \pm 1.84$ & $30.78 \pm 2.44$ & $29.27 \pm 2.07$ & $26.85 \pm 1.49$ & $24.90 \pm 1.01$ \\
$\mathrm{aHCO}_{3}^{-}, \mathrm{mmol} / \mathrm{L}(18.0-21.6)^{\mathrm{a}}$ & $22.47 \pm 2.02$ & $20.02 \pm 0.43$ & $19.54 \pm 0.42$ & $19.33 \pm 0.68$ & $17.71 \pm 0.67$ \\
$n=$ & 20 & 20 & 20 & 20 & 20 \\
\hline
\end{tabular}

$\mathrm{pCO}_{2}$ - partial pressure of $\mathrm{CO}_{2}$ in arterial blood; $\mathrm{aHCO}_{3}{ }^{-}$- bicarbonate concentration in arterial blood; $n$ - number of cats in each group; \pm - standard deviation.

${ }^{\mathrm{a}}$ Reference values of Uni-Lab Veterinary Diagnostic Laboratory (DiBartola, 2006).

2017, that in accordance with Article 1, Point 2.1 of the Act on the Protection of Animals Used for Scientific or Educational Purposes from January 15, 2015, this study did not require the approval of the Committee.

\section{RESULTS}

The comparison of the mean $\mathrm{ABB}$ parameters in the control group and in the groups of cats with various stages of CKD is presented in Table 3. In all groups, the arterial blood $\mathrm{pH}$ was similar. Similar observations were made in groups I, II and III with reference to the $\mathrm{pCO}_{2}$ and $\mathrm{aHCO}_{3}{ }^{-}$values. Results in group IV show signs of mild, compensated metabolic acidosis. According to the $\mathrm{H}-\mathrm{H}$ equation, none of the other animals had any ABB disorders.

The mean $\mathrm{Na}^{+}, \mathrm{K}^{+}, \mathrm{Cl}^{-}, \mathrm{P}_{\mathrm{i}}, \mathrm{HCO}_{3}{ }^{-}$and albumin concentrations in venous blood from the studied animals are presented in Table 4 . The concentration of serum ions, albumin and $\mathrm{HCO}_{3}{ }^{-}$in the control group (C) and in group I showed similar values and did not differ. The concentration of serum $\mathrm{Na}^{+}$in all groups was within the reference range. However, there was a significant difference in the $\mathrm{Na}^{+}$concentration between groups II, III and IV as well as between group I and the control group. The serum $\mathrm{K}^{+}$ concentration in all the cats was within the reference range, and it was significantly higher in group IV than in groups I and $\mathrm{C}$. The serum $\mathrm{Cl}^{-}$concentration in groups II, III and IV exceeded the upper reference limit for felines (hyperchloraemia) and differed significantly from the concentrations recorded in groups $\mathrm{C}$ and $\mathrm{I}$. The blood concentration of $\mathrm{Pi}$ in cats from groups I, II and III were within the reference range for that species and did not differ significantly from that of the control group. Despite the absence of statistically significant differences between the groups, there was a clear tendency of an increasing $P_{i}$ concentration in cats of group I, II and III, i.e. corresponding to the progression of CKD according to the IRIS scale. The concentration of $\mathrm{P}_{\mathrm{i}}$ was significantly higher in cats of group IV compared to those in the control group and in groups I, II and III (Table 4). The concentration of $\mathrm{HCO}_{3}{ }^{-}$in venous blood $\left(\mathrm{vHCO}_{3}{ }^{-}\right)$was also within the normal range and was significantly lower in group IV than in groups $C$ and I. Serum albumin concentration in groups III and IV was below the feline reference range (hypoalbuminaemia) and was significantly lower than that recorded in groups $\mathrm{C}$ and $\mathrm{I}$.

Table 5 presents the mean values of $A G, A G_{\text {corr }}, A_{\text {diff, }}$, $\mathrm{Cl}^{-} / \mathrm{Na}^{+}$and SID calculated based on the ion, $\mathrm{HCO}_{3}{ }^{-}$and albumin concentration in venous blood. The values of AG in all the animals were within the reference values for cats provided by Kaae and de Morais (2008), although the values in groups II, III and IV were significantly lower than those in groups $\mathrm{C}$ and $\mathrm{I}$. The values of $\mathrm{AG}_{\text {corr }}$ and SID calculated for the animals from groups $C$ and I were similar and did not differ significantly, while they were significantly higher than in the cats from groups II, III and IV. An opposite phenomenon was observed in the case of $\mathrm{AG}_{\text {diff }}$ value analysis this value was significantly lower in cats of groups $\mathrm{C}$ and I than in cats from groups II, III and IV.

The results of the $\mathrm{Cl}^{-} / \mathrm{Na}^{+}$ratio were consistent with those reported by Goggs et al. (2017) in all the cats, although

Table 4. Comparison of the mean $\mathrm{Na}^{+}, \mathrm{K}^{+}, \mathrm{Cl}^{-}, \mathrm{HCO}_{3}{ }^{-}$and albumin concentration (with mean values) in venous blood in the control group (C) and in cats with various stages of CKD (I-IV)

\begin{tabular}{lccrrr}
\hline & $\mathrm{C}$ & $\mathrm{I}$ & $\mathrm{II}$ & III & IV \\
\hline $\mathrm{Na}^{+}, \mathrm{mmol} / \mathrm{L}(144-156)^{\mathrm{b}}$ & $148 \pm 2.12$ & $147 \pm 3.03$ & $154^{\mathrm{a}} \pm 1.80$ & $152^{\mathrm{a}} \pm 1.34$ & $152^{\mathrm{a}} \pm 1.48$ \\
$\mathrm{~K}^{+}, \mathrm{mmol} / \mathrm{L}(4.10-5.60)^{\mathrm{b}}$ & $4.71 \pm 0.42$ & $4.67 \pm 0.23$ & $4.42 \pm 0.14$ & $4.72 \pm 0.29$ & $5.26^{\mathrm{a}} \pm 0.24$ \\
$\mathrm{Cl}^{-}, \mathrm{mmol} / \mathrm{L}(102-118)^{\mathrm{b}}$ & $106 \pm 3.01$ & $107 \pm 2.28$ & $120^{\mathrm{a}} \pm 1.27$ & $120^{\mathrm{a}} \pm 0.86$ & $121^{\mathrm{a}} \pm 1.46$ \\
$\mathrm{P}_{\mathrm{i}, \mathrm{mmol} / \mathrm{l}(1.45-2.60)^{\mathrm{b}}}$ & $1.20 \pm 0.14$ & $1.46 \pm 0.3$ & $1.56 \pm 0.16$ & $1.57 \pm 0.18$ & $4.01 \pm 1.07$ \\
$\mathrm{vHCO}_{3}{ }^{-}, \mathrm{mmol} / \mathrm{L}(18.0-23.2)^{\mathrm{b}}$ & $21.9 \pm 0.83$ & $21.4 \pm 0.69$ & $21.7 \pm 0.42$ & $21.4 \pm 0.51$ & $19.4^{\mathrm{a}} \pm 0.66$ \\
$\mathrm{Albumin}, \mathrm{g} / \mathrm{L}(27-39)^{\mathrm{b}}$ & $33 \pm 3.11$ & $32 \pm 2.43$ & $27^{\mathrm{a}} \pm 2.02$ & $24^{\mathrm{a}} \pm 1.51$ & $24^{\mathrm{a}} \pm 1.51$ \\
$n=$ & 20 & 20 & 20 & 20 & 20 \\
\hline
\end{tabular}

${ }^{\mathrm{a}} \mathrm{P}<0.001$ compared to group $\mathrm{C}$ and group $\mathrm{I} ; \mathrm{vHCO}_{3}{ }^{-}-$bicarbonate concentration in venous blood.

${ }^{\mathrm{b}}$ Reference values of Uni-Lab Veterinary Diagnostic Laboratory. 
Table 5. Comparison of the mean values of SID, $\mathrm{AG}, \mathrm{AG}_{\text {corr }}, \mathrm{AG}_{\mathrm{diff}}$ and $\mathrm{Cl} / \mathrm{Na}$ in the control group $(\mathrm{C})$ and in cats with various stages of CKD (I-IV)

\begin{tabular}{lccccc}
\hline & C & I & II & III & IV \\
\hline SID & $46 \pm 2.16$ & $45 \pm 3.89$ & $38^{\mathrm{a}} \pm 1.48$ & $37^{\mathrm{a}} \pm 1.37$ & $37^{\mathrm{a}} \pm 1.59$ \\
$\mathrm{AG}$ & $24.93 \pm 2.92$ & $24.03 \pm 3.85$ & $15.91^{\mathrm{a}} \pm 1.43$ & $15.47^{\mathrm{a}} \pm 1.65$ & $17.19^{\mathrm{a}} \pm 1.27$ \\
$\mathrm{AG}$ & $26.31 \pm 3.82$ & $25.68 \pm 4.17$ & $18.89^{\mathrm{a}} \pm 1.47$ & $19.17^{\mathrm{a}} \pm 1.65$ & $20.93^{\mathrm{a}} \pm 1.27$ \\
$\mathrm{AG}_{\text {diff }}$ & $1.37 \pm 0.52$ & $1.65 \pm 0.60$ & $2.97^{\mathrm{a}} \pm 0.50$ & $3.71^{\mathrm{a}} \pm 0.50$ & $3.68^{\mathrm{a}} \pm 0.37$ \\
$\mathrm{Cl} / \mathrm{Na}$ & $0.71 \pm 0.04$ & $0.71 \pm 0.02$ & $0.77^{\mathrm{a}} \pm 0.08$ & $0.78^{\mathrm{a}} \pm 0.01$ & $0.78^{\mathrm{a}} \pm 0.01$ \\
$n=$ & 20 & 20 & 20 & 20 & 20 \\
\hline
\end{tabular}

${ }^{a} \mathrm{P}<0.001$ compared to group $\mathrm{C}$ and group $\mathrm{I}$.

they were significantly higher in groups II, III and IV compared to the values found in groups $\mathrm{C}$ and I.

The results of $\mathrm{CBC}$ analysis of the venous blood did not vary, and all the parameters were within the reference range. Similarly, the glucose and lactate concentrations and the activities of ALT, ASP and alkaline phosphatase were within the normal limits.

\section{DISCUSSION}

The obtained results analysed in accordance with the guidelines issued for the interpretation of the classic model show that a compensated, mild metabolic acidosis was present only in group IV, as the blood concentration of $\mathrm{pCO}_{2}$ and the arterial $\mathrm{HCO}_{3}{ }^{-}$concentration were slightly below the reference range (Kellum, 2000; Kraut and Kurtz, 2005). The present findings are consistent with those of Elliott et al. (2003), who used this model in cats and found that the features of metabolic acidosis visible in the blood examination are evident only in an advanced stage of kidney failure. Similar results were obtained by Schück and Matousovic (2005) and Kraut and Kurtz (2005), who found that the ABB parameters in some people with CKD remain unchanged despite severe kidney damage. Human studies have found that the concentration of $\mathrm{HCO}_{3}{ }^{-}$was normal or slightly decreased in almost $20 \%$ of human patients with advanced CKD (Wallia et al., 1986; Caravaca et al., 1999). The normal concentration of $\mathrm{HCO}_{3}{ }^{-}$in groups II and III most likely results from the release of carbonates by the buffer reserve from bone, which is consistent with the views of other authors (Wallia et al., 1986; Caravaca et al., 1999; Ahn et al., 2012).

$\mathrm{Cl}^{-}$is the principal anion in the extracellular fluid. Hence, it is assumed that a decrease in plasma $\mathrm{Cl}^{-}$increases SID causing hypochloraemic alkalosis, while an increase in plasma $\mathrm{Cl}^{-}$often decreases SID causing hyperchloraemic acidosis (Goggs et al., 2017). Therefore, the statistically significant increase in chlorine concentration, a decrease in $\mathrm{HCO}_{3}{ }^{-}$concentration and the unchanged AG value signified hyperchloraemic (i.e. normal or low AG) metabolic acidosis in groups II, III and IV. This is consistent with the observations of Hopper and Epstein (2012), who stated that hyperchloraemic metabolic acidosis appears to be more common in cats than a high-AG metabolic acidosis. The AG values were within the reference range in all groups, although they were significantly lower in groups II, III and IV than in groups $\mathrm{C}$ and $\mathrm{I}$, which, according to the findings of Kraut and Madias (2007), indicates the worsening of hyperchloraemic metabolic acidosis. According to Hopper et al. (2014a) and Feldman et al. (2005), a decrease in the AG value may result from a low blood albumin concentration, which was observed in the present study.

Many authors believe that AG should be corrected if it is to be used to assess metabolic disorders, i.e., its value should be adjusted to correspond to the actual concentration of albumin, a protein blood buffer, the concentration of which can rapidly decrease in the course of metabolic diseases (Figge et al., 1998; Feldman et al., 2005; Hopper and Epstein, 2012). In human medicine, the concept of a modified AG takes into account the concentration of the protein blood buffer and combines the classic model with the Stewart model (Fencl et al., 2000). Due to the fact that there are no other reports of $\mathrm{AG}_{\text {corr }}$ values in cats, the current results cannot be compared with those of other studies. The $\mathrm{AG}_{\text {corr }}$ values in group $\mathrm{C}$ and group I were similar to those reported in healthy dogs (Vanova-Uhrikova et al., 2017). Small differences resulted from different reference thresholds of serum albumin concentrations - 39 $\mathrm{g} / \mathrm{L}$ in the present study and $29.5 \mathrm{~g} / \mathrm{L}$ reported by VanovaUhrikova et al. (2017). The $\mathrm{AG}_{\text {corr }}$ values calculated in cats in groups II-IV were the same as those calculated in children (Hatherill et al., 2002), whose blood albumin levels were similar to those in the studied cats. In human medicine, it is believed that if the difference between $A G$ and $\mathrm{AG}_{\text {corr }}$ exceeds 2-3, unidentified anions, associated with a worse patient prognosis, may be present (Balasubramanyan et al., 1999). In the case of renal failure, such anions usually include hippurans, which are formed intermediately in the Krebs cycle and are considered to be uraemic toxins appearing in the blood as a result of progressive impairment of glomerular filtration in the course of CKD (Vanholder et al., 2003, 2009). In the present study, the obtained difference $\left(A G_{\text {diff }}\right)$ between the $A G$ and $A G_{\text {corr }}$ in groups II, III and IV amounted to $2.97,3.71$ and 3.68, respectively, which may be an indicator of the presence of uraemic toxins.

Some authors believe that the $\mathrm{Cl}^{-} / \mathrm{Na}^{+}$ratio is a more accurate and better indicator of $\mathrm{ABB}$ disorders than $\mathrm{AG}$ (Durward et al., 2001; Goggs et al., 2017). In the case of 
high-AG metabolic acidosis, Durward et al. (2001) demonstrated the usefulness of the $\mathrm{Cl}^{-} / \mathrm{Na}^{+}$ratio, which decreased with the decrease of blood $\mathrm{Cl}^{-}$concentrations and an increase in the AG. However, the $\mathrm{Cl}^{-} / \mathrm{Na}^{+}$ratio does not appear to be more useful than AG in the case of hyperchloraemic metabolic acidosis. In this study, the $\mathrm{Cl}^{-} / \mathrm{Na}^{+}$ ratio was significantly higher in the cats from groups II, III and IV compared to groups $\mathrm{C}$ and I, supporting its usefulness in the diagnosis of hyperchloraemic metabolic acidosis. However, the values of the $\mathrm{Cl}^{-} / \mathrm{Na}^{+}$ratio remained within the range provided by Goggs et al. (2017) in all the groups (0.74-0.80), including group IV diagnosed with metabolic acidosis based on the Henderson-Hasselbalch equation $\mathrm{(HH}$ equation). Based on this study, the upper reference range of the $\mathrm{Cl}^{-} / \mathrm{Na}^{+}$ratio in cats with suspected $\mathrm{CKD}$ should approximate $0.77-0.78$. This is supported by the findings of the $\mathrm{Cl}^{-} / \mathrm{Na}^{+}$ratio in the cats from groups II and III, which were diagnosed with hyperchloraemic metabolic acidosis based on the $A G$, the $A_{\text {corr }}$ and the difference between those two values. Moreover, the SID value was decreased in cats from groups II, III and IV, which, according to the Stewart model, clearly indicates metabolic acidosis both in humans (Durward et al., 2001; McCullough and Constable, 2003; Corey, 2005) and cats (Hopper et al., 2014a). Based on their results, the authors of this study concluded that an analysis of the changes in SID and AG is more precise, reliable and simpler in the diagnosis of metabolic acidosis than the classic model. This is supported by the results of Hopper et al. (2014a), who compared three methods of acidbase analysis in dogs and cats and found greater diagnostic utility of the method based on the Stewart model. Our findings are consistent with the conclusions of Morgan (2009), who claimed that the diagnosis of ABB disorders in the course of kidney failure should be based primarily on the Stewart model.

Contrary to the findings of Elliott et al. (2003), a significant increase in the blood concentration of $\mathrm{Cl}^{-}$with an increase in the stage of CKD was seen in this study. However, this result is consistent with the findings of Hopper and Epstein (2012), who observed hyperchloraemia in 37\% of cats with diagnosed metabolic acidosis. Hopper and Epstein (2012) defined hyperchloraemia as an increase in blood $\mathrm{Cl}^{-}$ concentration above $124 \mathrm{mmol} / \mathrm{L}$, hence above the values obtained in this study. Hypokalaemia is known to occur in $18-30 \%$ of cats with CKD (Elliott and Barber, 1998; Elliott et al., 2003; Reynolds and Lefebvre, 2013; Bartges, 2012). This phenomenon was not observed in our results, although a significant increase in serum $\mathrm{K}^{+}$concentration was seen in the cats of group IV. This is consistent with the findings of other authors, who noted an increased $\mathrm{K}^{+}$concentration in the same stage of $\mathrm{CKD}$, owing to reduced potassium excretion (Elliott and Barber, 1998; Elliott et al., 2003; Paepe and Daminet, 2013).

According to the authors, the changes in ion concentration in the course of CKD require further analysis. They may be dependent on the site of nephron damage and may also be associated with the presence, severity or absence of vomiting.
Based on the obtained results we can conclude that $\mathrm{ABB}$ analysis using the classic model enabled the detection of $\mathrm{ABB}$ disorders in cats in IRIS stage IV of CKD. However, the analysis of the $A G, A G_{\text {corr }}$ and $A_{\text {diff }}$ values allow us to diagnose ABB disorders even in cats in IRIS stages II and III of $\mathrm{CKD}$. The analysis of concentration changes in the course of $\mathrm{CKD}$ is a more precise tool for the detection of $\mathrm{ABB}$ than the classic model. Our results suggest that the blood ion concentrations should be monitored regularly in cats diagnosed with stage I of CKD based on SDMA concentration in order to analyse the $\mathrm{AG}, \mathrm{AG}_{\text {corr }}, \mathrm{AG}_{\text {diff }}$ and $\mathrm{Cl}^{-} / \mathrm{Na}^{+}$ratio. This may allow early diagnosis of $\mathrm{ABB}$ disorders and the implementation of an effective therapy. Further research on this topic is warranted.

\section{REFERENCES}

Ahn, H., Kim, J. M., Lee, K., Kim, H. and Jeong, D. (2012): Extracellular acidosis accelerates bone resorption by enhancing osteoclast survival, adhesion, and migration. Biochem. Biophys. Res. Commun. 418, 144-148.

Balasubramanyan, N., Havens, P. L. and Hoffman, G. M. (1999): Unmeasured anions identified by the Fencl-Stewart method predict mortality better than base excess, anion gap, and lactate in patients in the pediatric intensive care unit. Crit. Care Med. 27, 1577-1581.

Bartges, J. W. (2012): Chronic kidney disease in dogs and cats. Vet. Clin. North Am. Small Anim. Pract. 42, 669-692.

Brown, C. A., Elliott, J., Schmiedt, C. W. and Brown, S. A. (2016): Chronic kidney disease in aged cats: clinical features, morphology, and proposed pathogenesis. Vet. Pathol. 53, 309-326.

Caravaca, F., Arrobas, M., Pizarro, J. L. and Espárrago, J. F. (1999): Metabolic acidosis in advanced renal failure: differences between diabetic and nondiabetic patients. Am. J. Kidney Dis. 33, 892-898.

Casaletto, J. J. (2005): Differential diagnosis of metabolic acidosis. Emerg. Med. Clin. North Am. 23, 771-787.

Chakrabarti, S., Syme, H. M. and Elliott, J. (2012): Clinicopathological variables predicting progression of azotemia in cats with chronic kidney disease. J. Vet. Intern. Med. 26, 275-281.

Congdon, J. M., Marquez, M., Niyom, S. and Boscan, P. (2013): Cardiovascular, respiratory, electrolyte and acid-base balance during continuous dexmedetomidine infusion in anesthetized dogs. Vet. Anaesth. Analg. 40, 464-471.

Constable, P. D. (2000): Clinical assessment of acid-base status: comparison of the Henderson-Hasselbalch and strong ion approaches. Vet. Clin. Pathol. 29, 115-128.

Corey, H. E. (2005): Bench-to-bedside review: fundamental principles of acid-base physiology. Crit. Care 9, 184-192.

De Brito-Ashurst, I., Varagunam, M., Raftery, M. J. and Yaqoob, M. M. (2009): Bicarbonate supplementation slows progression of CKD and improves nutritional status. J. Am. Soc. Nephrol. 20, 2075-2084.

Dębowska, M., Jędras, M. and Matuszkiewicz-Rowińska, J. (2013): Treatment of metabolic acidosis in chronic kidney disease. Nefrol. Dial. Pol. 17, 113-115. 
DiBartola, S. (2006): Introduction to acid-base disorders. In: Stringer, S. (ed.), Fluid, Electrolyte and Acid-Base Disorders in Small Animal Practice, 3rd ed. Saunders.

Di Iorio, B., Aucella, F., Conte, G., Cupisti, A. and Santoro, D. (2012): A prospective, multicenter, randomized, controlled study: the correction of metabolic acidosis with use of bicarbonate in Chronic Renal Insufficiency (UBI) Study. J. Nephrol. 25, 437-440.

Durward, A., Skellett, S., Mayer, A., Taylor, D., Tibby, S. M. and Murdoch, I. A. (2001): The value of the chloride: sodium ratio in differentiating the aetiology of metabolic acidosis. Intens. Care Med. 27, 828-835.

Elliott, J. and Barber, P. J. (1998): Feline chronic renal failure: clinical findings in 80 cases diagnosed between 1992 and 1995. J. Small Anim. Pract. 39, 78-85.

Elliott, J., Syme, H. M., Reubens, E. and Markwell, P. J. (2003): Assessment of acid-base status of cats with naturally occurring chronic renal failure. J. Small Anim. Pract. 44, 65-70.

Emmett, M. (2006): Anion-gap interpretation: the old and the new. Nat. Clin. Pract. Nephrol. 2, 4-5.

Feldman, M., Soni, N. and Dickson, B. (2005): Influence of hypoalbuminemia or hyperalbuminemia on the serum anion gap. J. Lab. Clin. Med. 146, 317-320.

Fencl, V., Jabor, A., Kazda, A. and Figge, J. (2000): Diagnosis of metabolic acid-base disturbances in critically ill patients. Am. J. Respir. Crit. Care Med. 162, 2246-2251.

Figge, J., Jabor, A., Kazda, A. and Fencl, V. (1998): Anion gap and hypoalbuminemia. Crit. Care Med. 26, 1807-1810.

Finch, N. (2014): Measurement of glomerular filtration rate in cats: methods and advantages over routine markers of renal function. J. Feline Med. Surg. 16, 736-748.

Goggs, R., Myers, M., De Rosa, S., Zager, E. and Fletcher, D. J. (2017): Chloride: sodium ratio may accurately predict corrected chloride disorders and the presence of unmeasured anions in dogs and cats. Front. Vet. Sci. 4, 122-130.

Hall, J. A., Yerramilli, E., Obare, M., Yerramilli, M. and Jewell, D. E. (2014): Comparison of serum concentrations of symmetric dimethylarginine and creatinine as kidney function biomarkers in cats with chronic kidney disease. J. Vet. Intern. Med. 28, $1676-1683$.

Han, X. and Chesney, R. W. (2012): The role of taurine in renal disorders. Amino Acids 43, 2249-2263.

Hatherill, M., Waggie, Z., Purves, L., Reynolds, L. and Argent, A. (2002): Correction of the anion gap for albumin in order to detect occult tissue anions in shock. Arch. Dis. Child. 87, 526-529.

Hokamp, J. A. and Nabity, M. B. (2016): Renal biomarkers in domestic species. Vet. Clin. Pathol. 45, 28-56.

Hopper, K. and Epstein, S. E. (2012): Incidence, nature, and etiology of metabolic acidosis in dogs and cats. J. Vet. Intern. Med. 26, 1107-1114.

Hopper, K., Epstein, S. E., Kass, P. H. and Mellema, M. (2014a): Evaluation of acid-base disorders in dogs and cats presenting to an emergency room. Part 1: comparison of three methods of acid-base analysis. J. Vet. Emerg. Crit. Care 24, 493-501.

Hopper, K., Epstein, S. E., Kass, P. H. and Mellema, M. (2014b): Evaluation of acid-base disorders in dogs and cats presenting to an emergency room. Part 2: comparison of anion gap, strong ion gap, and semiquantitative analysis. J. Vet. Emerg. Crit. Care 24, 502-508.

Kaae, J. and De Morais, H. A. (2008): Anion gap and strong anion gap: a quick reference. Vet. Clin. North Am. Small Anim. Pract. 38, 443-447.

Kellum, J. A. (2000): Determinants of blood $\mathrm{pH}$ in health and disease. Crit. Care 4, 6-14.

Kraut, J. A. and Kurtz, I. (2005): Metabolic acidosis of CKD: diagnosis, clinical characteristics, and treatment. Am. J. Kidney Dis. 45, 978-993.

Kraut, J. A. and Madias, N. E. (2007): Serum anion gap: its uses and limitations in clinical medicine. Clin. J. Am. Soc. Nephrol. 2, 162-174.

McCullough, S. M. and Constable, P. D. (2003): Calculation of the total plasma concentration of non-volatile weak acids and the effective dissociation constant of nonvolatile buffers in plasma for use in the strong ion approach to acid-base balance in cats. Am. J. Vet. Res. 64, 1047-1051.

McLeland, S. M., Cianciolo, R. E., Duncan, C. G. and Quimby, J. M. (2015): A comparison of biochemical and histopathologic staging in cats with chronic kidney disease. Vet. Pathol. 52, 524-534.

Morgan, T. J. (2009): The Stewart approach - one clinician's perspective. Clin. Biochem. Rev. 30, 41-54.

Morris, C. G. and Low, J. (2008): Metabolic acidosis in the critically ill: part 1. Classification and pathophysiology. Anaesth. 63, 294-301.

Paepe, D. and Daminet S. (2013): Feline CKD. Diagnosis, staging and screening - what is recommended? J. Feline Med. Surg. 15, 15-27.

Reynolds, B. S. and Lefebvre, H. P. (2013): Feline CKD. Pathophysiology and risk factors - what do we know? J. Feline Med. Surg. 15, 3-14.

Schück, O. and Matousovic, K. (2005): Relation between pH and the strong ion difference (SID) in body fluids. Biomed. Papers 149, 69-73.

Smuszkiewicz, P. and Jakieła-Sokołowska, A. (2011): Interpretation of acid-base disorders in patients treated in Intensive Care Unit. Is the traditional approach sufficient? Anest. Ratow. 5, 371-380.

Sparkes, A. H., Caney, S., Chalhoub, S., Elliott, J., Finch, N., Gajanayake, I., Langston, C., Lefebvre, H. P., White, J. and Quimby, J. (2016): ISFM consensus guidelines on the diagnosis and management of feline chronic kidney disease. J. Feline Med. Surg. 18, 219-239.

Stewart, P. A. (1978): Independent and dependent variables of acid-base control. Respir. Physiol. 33, 9-26.

Stewart, P. A. (1983): Modern quantitative acid-base chemistry. Can. J. Physiol. Pharmacol. 61, 1444-1461.

Vanholder, R., Abou-Deif, O., Argiles, A., Baurmeister, U., Beige, J., Brouckaert, P., Brunet, P., Cohen, G., De Deyn, P. P., Drüeke, T. B., Fliser, D., Glorieux, G., Herget-Rosenthal, S., Hörl, W. H., Jankowski, J., Jörres, A., Massy, Z. A., Mischak, H., Perna, A. F., Rodriguez-Portillo, J. M., Spasovski, G., Stegmayr, B. G., Stenvinkel, P., Thornalley, P. J., Wanner, C. and Wiecek, A. (2009): The role of EUTox in uremic toxin research. Semin. Dial. 22, 323-328. 
Vanholder, R., De Smet, R., Glorieux, G., Argilés, A., Baurmeister, U., Brunet, P., Clark, W., Cohen, G., De Deyn, P. P., Deppisch, R., Descamps-Latscha, B., Henle, T., Jörres, A., Lemke, H. D., Massy, Z. A., Passlick-Deetjen, J., Rodriguez, M., Stegmayr, B., Stenvinkel, P., Tetta, C., Wanner, C. and Zidek, W. (2003): Review on uremic toxins: classification, concentration, and interindividual variability. Kidney Int. 63, 1934-1943.
Vanova-Uhrikova, I., Rauserova-Lexmaulova, L., Rehakova, K., Scheer, P. and Doubek, J. (2017): Determination of reference intervals of acid-base parameters in clinically healthy dogs. J. Vet. Emerg. Crit. Care 27, 325-332.

Wallia, R., Greenberg, A., Piraino, B., Mitro, R. and Puschett, J. B. (1986): Serum electrolyte patterns in end-stage renal disease. Am. J. Kidney Dis. 8, 98-104. 